\section{SOI: $1.1 /$ TAS DOI: $10.15863 /$ TAS International Scientific Journal Theoretical \& Applied Science}

p-ISSN: 2308-4944 (print)

e-ISSN: 2409-0085 (online)

Year: 2018

Issue: 03

Volume: 59

Published: 20.03.2018

http://T-Science.org

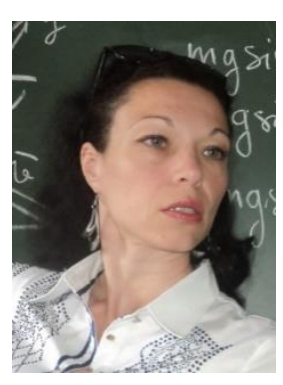

Tetiana P. Golub

$\mathrm{PhD}$, Associate Professor, National Technical University of Ukraine "Igor Sikorsky Kyiv Polytechnic Institute"

SECTION 5. Innovative technologies in science.

\title{
FORESIGHT TECHNOLOGY IN MODERN SCIENCE DEVELOPMENT
}

Abstract: The article deals with the foresight technology study as not just the study of the future, but also a set of approaches to decision-making with the aim of improving the factors affecting the future in the long run, and creating broad social networks to form the desired or expected future in modern conditions of technical and informational revolution.

Key words: foresight, science, technology, approaches.

Language: English

Citation: Golub TP (2018) FORESIGHT TECHNOLOGY IN MODERN SCIENCE DEVELOPMENT. ISJ Theoretical \& Applied Science, 03 (59): 128-133.

Soi: http://s-o-i.org/1.1/TAS-03-59-19 Doi: crossef https://dx.doi.org/10.15863/TAS.2018.03.59.19

\section{Introduction}

Over the last 300 years the role of science has radically changed. From aristocratic occupation, akin to a hobby, inquisitive units, scientific research has become a mass occupation, the profession of millions. Science has become the starting point and source of technological progress. And technology, based on scientific knowledge, has become the basis of production. In the twentieth century, the revolution of technology came to replace the scientific revolution.

In the second half of the twentieth century, the economy began to turn into a knowledge economy, and developed societies into so-called knowledge societies. The success of modern societies has become less dependent on the size of the country's territory or population, and increasingly on its innovative development and innovative activity, on the realization of knowledge in production and human potential. To maintain high competitive advantages and sustainable development, successful societies need a high rate of innovation. And innovations are not only new products, methods and organization of their production, but also new services.

In the context of globalization, social and economic evolution in general, and the development of the knowledge society in particular, are accelerating significantly, which gives additional opportunities for development to the level of highly developed societies. In such conditions the role of the decisions made today and their price for the future are significantly increasing. It is important to understand the vector of development and long-term social and economic, scientific and technological, humanitarian and environmental context.

For the effective development and reasonable distribution of public potential and resources, various approaches and methods are used to understand, foresee and shape the future, to determine the goals and development trends, the tasks of management and ways to achieve these objectives. Over the past 50 (and especially last 15) years, foresight has spread widely and developed significantly.

For the justification of strategic and even tactical solutions, in conditions of rapidly changing public practice, forecasting and especially foresight research is widely used. In fact, they are becoming almost the most effective instruments of scientific, technological and innovation policy in the context of globalization.

It is known that foresight research is not identical to forecasts, which were made 50 and even 30 years ago. In general, futures studies were formed as the most complete set of prediction methods. They include the study and consideration of the most important trends and factors, as well as the identification of the main interests and the analysis of combination of different forces with the aim of determining the alternatives for the future development to a much greater extent than making only the forecast of the future. Futures studies are heavily influenced by such problems as ecology, 
human health, new technologies, i.e., have an unconditional social orientation [1].

The term foresight began to be actively used since the late 1980s. This term means not only the study of the future, but also a set of approaches to decision-making with the aim of improving the factors affecting the future in the long run, and creating broad social networks to form the desired or expected future. In this sense, the interpretation of foresight as a social technology that outlines the direction and ways of shaping the future and requires discussion of options for the development of this future and scenarios by its various social groups, forces (or agents, as they are called) is justified.

These approaches to making decisions to determine and achieve the expected future have the following objectives:

gather key social agents of change and sources of knowledge;

these agents are gathered together to develop a strategic vision and forecast for the future;

the focus is on long-term social, economic and technological development;

the formal output of the work may include scenarios, action plans, priority lists;

however, the foresight process, especially in the area of creating links between people, should help to create a common vision for the future, an overall picture of the future.

It is known that foresight concerns various spheres of social activity and differs in the subject and richness of the methods used and needed to study this subject. Foresight can be divided into classes:

in terms of problem coverage: global, national, local, etc;

in the spheres of foresight: social, economic, political, scientific, technological, educational, etc;

at different levels within the investigated spheres, for example, within the economic sphere it is sectoral, cluster, corporate, etc.

Of course, a combination of several types of foresight is possible depending on the goals and objectives of the study.

Foresight is different in terms of a time lag coverage, or a time horizon: it can be medium- or long-term, but it is very important; rather, it should be phased and be monitored.

Various methods are used to implement foresight:

brainstorming of experts,

creating and developing scenarios,

the Delphi method,

SWOT analysis,

alternative options,

international comparisons, etc.

It should be emphasized, that a quality foresight, especially at the national and global levels, involves the use of a whole variety of methods, rather than one or two of them: the picture will not be complete enough.

In modern world, foresight is becoming a widespread policy tool, especially in science, technology and innovation, but not only. The most global foresight on the goals, tasks and level of problems studied is implemented by the American Council of the United Nations University in the framework of the Millennium Project, launched in 1996.

Of course, this type of predictive global research did not come about by chance. Back in the 1970s, intellectuals, united in the Club of Rome, analyzed the global problems facing humanity as a whole, trying to see their future solution. But then there were not so many different methods of foresight of the future, like the modern ones. Therefore, long-term forecasts were mostly futurological, often alarmist in nature.

The organization of the Millennium Project differs from its predecessors. The project experts analyze the main problems of the present, facing humanity as a whole and individual sub-regions and countries. For this, various methods are used - the Delphi method, the construction of development scenarios, the development of own indicators of the future state, etc. The project organizers managed to gather a huge team of experts under the leadership of strong leaders with the help of approved, welldeveloped methods of collecting, processing information and its qualitative analysis.

Annually within 10 years the next volume of the report of the Millennium project "State of the Future" was published. It is interesting to note that since 1999, in the key terms used in these reports, "issues and opportunities" to the notion of "problems and opportunities for solutions" the concept of "challenge" was added, i.e. Challenge has become a binary concept, synthesis, or removal of problems and solutions. After all, reality is formed or, it is better to say, is corrected by the combined influence of both [2-4]. So it was recorded that the adequacy and depth of the decision, and ultimately the formation of reality, depends on the accuracy and quality of problems understanding. Thus, foresight has not only analytical and methodological significance, but also technological, which many researchers in the world pay attention to [4].

Millenium project experts identify 15 world problems, including:

achieving sustainable development,

balanced growth of the world's population,

providing people with water, food and fuel, combating old and new diseases,

free access to information and development of information and communication technologies, strategies development,

not giving freedom to terrorism and ethnic conflicts, the criminal world, 


\begin{tabular}{|c|c|c|c|c|c|c|}
\hline Impact Factor: & $\begin{array}{l}\text { ISRA (India) } \\
\text { ISI (Dubai, UAE } \\
\text { GIF (Australia) } \\
\text { JIF }\end{array}$ & $\begin{array}{l}=1.344 \\
=0.829 \\
=0.564 \\
=1.500\end{array}$ & $\begin{array}{l}\text { SIS (USA) } \\
\text { PИНЦ (Russia) } \\
\text { ESJI (KZ) } \\
\text { SJIF (Morocco) }\end{array}$ & $\begin{array}{l}=0.912 \\
=0.207 \\
=4.102 \\
=2.031\end{array}$ & $\begin{array}{l}\text { ICV (Poland) } \\
\text { PIF (India) } \\
\text { IBI (India) }\end{array}$ & $\begin{array}{l}=6.630 \\
=1.940 \\
=4.260\end{array}$ \\
\hline
\end{tabular}

social freedom of women,

development of democracy,

development of effective political decisions,

harmonious relations between rirodoy and

society,

a new global ethics etc [2].

When discussing these global pressing problems of mankind and the planet as a whole, many decisions rest on the development and application of modern technologies. However, the scientific and technological foresight is being developed for the long-term perspective up to 2025, 2050 within the framework of this project, including scenarios. For example:

1. Science and technology develop their own way of life;

2. The world awakens;

3. Open the gates about the dangers of irresponsible development and the application of science;

4. Negative reaction of the whole population in relation to science [3].

Such an approach rather cautions both excessive kindness and technocratic approaches to science and life. It has other tasks - the definition of the social significance of scientific and technological progress with a view to achieving sustainable development in the world and individual subregions and countries.

In all developed and in many developing countries, strategic planning of priority areas of research, development and innovation is carried out. National plans and projects for the development of science and technology are being formed. Taking into account the fact that technologies strongly influence not only production, which is important in itself, as it changes the character and productivity of labor, it requires qualitative special education and skills, etc., but their influence is more extensive.

Technologies affect both nature and society and individuals in domestic sphere, in healthcare, in the sphere of communication and leisure, etc. in general, on the conditions of work and life. The spread and influence of technology on the life of man and society is strengthened by the development of globalization, the rapid spread of technology and their successful applications in all major spheres of life.

Foresight at the present stage of its development, as a rule, increasingly includes a social context that takes into account demographic and geographical changes, cultural and political changes, forms of economic organizations and other factors. The problem that often arises in scientific and technological forecasts is that they only take into account the importance of broader economic, social and cultural factors. Meanwhile, one of the conditions for these forecasts fulfillment is the social factor.
It was mentioned that foresight can be applied to social, political and cultural problems. But even if foresight is aimed at scientific and technological issues, it will be different from simply predicting the development of technology. The vision of the future in the long term is of scientific interest and has practical significance - it allows to take into account the impact on the future state of today's actions that may have a delayed effect in time and have a series of risks. Thus, power stations and roads should be built taking into account future changes in requests, and teachers for future generations will learn today. Tomorrow's scientists and intellectual leaders are trained and educated today. And the idea of where people live and how they work and spend their leisure affects the development of cities, service systems, etc.

Attention to innovations in the foresight process can solve the problem of choosing priorities and thus determine the further path of social development. Social goals and social innovations, such as new approaches to caring for different social strata and groups, especially those that are weakened, new ways of organizing the workplace and time, methods and channels for the regulation and coordination of employment, etc. should be taken into account. The vision of the future can be useful for citizens who make their choice of a way of life, profession on the basis of ideas about the future.

Some groups of people, especially socially active groups, can make a more complete and wellgrounded opinion about the future in the process of communication and exchange of information with other foresight participants. This will greatly help them in developing a strategy for living, behaving and doing business.

Globalization develops and spreads, becoming more and more real and inevitable. It is globalization that creates the main social and structural challenges for societies nowadays. World economic systems are associated with trade, investment, financial flows and well-educated people, who are now more mobile than ever. The rapid expansion of globalization literally transfers North America, Europe and other subregions to an increasingly boundless area with great opportunities and strong challenges.

Below we will consider some of the main trends identified in various reports of foresight [2-10]:

* Competition is no longer connected with national borders, as it was before. Instead, successful local, regional or sectoral environments compete with each other, regardless of national identity. Local firms invest and trade globally, i.e. for them there are literally no boundaries.

* Vital energy supplies for a large part of the developed and developing world are carried out from outside, from abroad. 


\begin{tabular}{|c|c|c|c|c|c|c|}
\hline Impact Factor: & $\begin{array}{l}\text { ISRA (India) } \\
\text { ISI (Dubai, UAE } \\
\text { GIF (Australia) } \\
\text { JIF }\end{array}$ & $\begin{array}{r}=1.344 \\
=0.829 \\
=0.564 \\
=1.500\end{array}$ & $\begin{array}{l}\text { SIS (USA) } \\
\text { PИНЦ (Russia) } \\
\text { ESJI (KZ) } \\
\text { SJIF (Morocco) }\end{array}$ & $\begin{array}{l}=0.912 \\
=0.207 \\
=4.102 \\
=\mathbf{2 . 0 3 1}\end{array}$ & $\begin{array}{l}\text { ICV (Poland) } \\
\text { PIF (India) } \\
\text { IBI (India) }\end{array}$ & $\begin{array}{l}=6.630 \\
=1.940 \\
=4.260\end{array}$ \\
\hline
\end{tabular}

* Technologies are mainly developed at the global level, most often they do not have their own country of origin.

* The impact of globalization is also felt within societies; there is an ever more acute sense of "tension lines" between the approaches of different cultures, population groups and political forces that must and are compelled to find consensus on vital issues. In these processes - finding consent and joint acceptable solutions - a new global ethics of humanity is being developed.

And this happens not only at the level of global political, economic or social and cultural organizations like the UN, UNESCO, UNIDO, WTO, VTB, WWF, OECD, EU. This process takes place at the global, sub-regional, national, regional and local levels simultaneously.

Modern people have more free time to travel, see other peoples and cultures. Global patterns of life and culture are being developed more and more, leading to stronger links and associations with global ideas and standards of life, and also to greater diversity within local culture.

For example, Europe as a whole within the expanding European Union becomes ethnically and culturally more diverse, while the global urban lifestyle becomes attractive to younger and older generations in different societies. If at present about $50 \%$ of the world's population lives in cities, then by 2020 it is expected that it will reach 80\% [2]. Accompanying the process of population urbanization, the individualization and even atomization of communities, the emergence of new social groups and changing values offer new opportunities for the introduction and development of new products and services and provide significant potential for economic growth.

All countries are preparing for the development of the knowledge society, since knowledge has become the most important factor of competitiveness:

At the national, regional and local levels, it becomes vital in every single company to develop the use of knowledge in various ways.

Multidisciplinary and co-operational skills will increasingly be key to any industry. At the same time, competition for skills and talent will require the search for new forms of work organization.

Various foresight studies lead to the conclusion that the demand for competent experts in the future will require the development of the educational system in accordance with the social change and the principle of lifelong learning. The synonym for literacy is the ability to a constant, lifelong learning.

In order to take into account the new challenges of globalization, the knowledge society in an increasing number of countries is carrying out active studies of the future and an analysis of already used and developed approaches.

In the unification and urbanization of the world, in which cities compete with each other to attract domestic investment, local authorities seek to create high-quality, healthy, attractive environments for their citizens, and to attract firms from other places. Virtually all industrial countries compete to create dynamically developing areas. Various reports on future research have identified challenges that will affect regional differences and social security:

* One of the main challenges of the future is the problem of urban congestion with regional concentration of the economy.

* The growth of urban centers and regions will give rise to serious challenges to the capacity of local authorities to provide adequate services such as education and training, social welfare and child welfare services, regional infrastructure, community development and family services, etc.

The main difficulties affecting local solutions in the field of knowledge-intensive industries concern the vital aspects of life: urban cultural and environmental values, regional opportunities, convenient transport communications, high-quality telecommunications systems, and the quality and labor cost. Restoration of the environment, urban restructuring and the healthy functioning of urban centers clearly must become important elements of sustainable economic development and interregional unity throughout the world. Modern civilization is primarily a city civilization.

* There will be a growing need for the development and concentration of high-quality interdisciplinary expertise in regions in order to maintain the necessary level of education, health and industry centers.

But the development of technologies and innovations, which are the basis of economic progress and globalization of the modern world, in the projection for the future will require not only changes in the basic spheres of people's livelihoods labor, life reproduction and basic life resources, communication and leisure. They concern not only the economy, but also politics, law, etc. The values and patterns of activity and behavior that will require legislative changes in relation to information, climate, human health, etc. are changing and will change.

The development of information and communication technologies (ICT) as an important part of the modern technological revolution, the development of the knowledge society, especially accelerated with the advent of the Internet and digital solutions. According to foresight studies [2 - 10], ICT will continue to have a critical impact on the development of all industries and social sectors. The digital revolution, with its new communications and 
information technology, is changing society and ways of life.

* A special problem in this area is the security of ICT systems and the confidentiality of information. This affects the competitiveness and success of the business.

* There will be a growing need for human resources, capable of adapting and adapting new technologies in the economy and society in general. There will be a growing need for continuous and direct training.

* There will also be a strong need for a developed technological infrastructure. Mobile communication, broadband, electronic services, embedded systems, artificial intelligence, cognitive science, microsystems, electronic or intellectual paper, sensors and the semantic network and nanotechnologies are also mentioned in various forms of foresight among the components that form the infrastructure of the future.

Another important block of problems included in a socially-oriented foresight, whether scientific, technological, innovative, global, national or regional foresight - is the problems of the environment and climate. Attention to environmental aspects of existence requires significant changes in products, services, methods and processes of production. Such changes will require new technological solutions.

At the same time, new values and goals related to the environment create new business opportunities that can be beneficial for developers of new products and services:

The sustainability of development is largely determined by the way products and production systems are developed with a prospect for the future. Sustainability is provided by the ways in which production systems and their products are developed, while the ecological aspect, the health of the planet, nature and people becomes very important condition of sustainability.

Climatic problems are largely related to the production, consumption and conservation of energy, with policy in the energy sector in general. Climate change poses a serious threat to the way of life, the infrastructures that are created in the Western world, and not only there.

At the same time, these challenges serve as a driving force for technological development and the formation of systems and products in order to reduce the impact of people on the climate and possibly manage it.

The energy problem is acute all over the world, as well as the creation of alternative (oil and natural gas) fuels. This is very important for maintaining sustainable development. It is obvious that control over important natural resources, especially energy resources, can lead to serious regional or global conflicts. This all the more urges us to seek and develop alternatives that are viable and profitable in the long term.

\section{Conclusions}

Scientific and technological innovations are often a source of significant economic and social and cultural changes, as it was due to the development of ICT. Thus, the uncertainty of scientific and technological forecasts is quite high, although the precedents of modern top technologies development are taught to be more attentive and far-sighted. As a consequence, it is impossible to accurately identify specific areas of research that will contribute to solving social and economic challenges.

Challenges faced by different countries due to the application of scientific and technological innovations can vary significantly due to traditions, the level of economic and cultural development, the development of human resources, the type of government, etc.

The significance of a call, or a problem that needs to be addressed, can change rapidly, depending on economic, political and even technological influences. The value of the identified call could change in a relatively short time or because of objective events. Therefore, it is difficult to draw general conclusions about the importance of various challenges.

All this is a factor of uncertainty and risk in scientific and technological foresights.

One way or another, both the regional and the national foresight are facing global problems of human development and a technological revolution. And in carrying out these foresights, key application areas such as safety, health, social and cultural life, education, state and regional management, management of trade and services were taken into account. Critical problems encountered in the application of technology were also taken into account. risks that can be grouped into the following classes: hazard to man, danger to culture, danger to management, danger to nature.

The success of development in a globalizing world is facilitated by many mechanisms and tools, especially in decision-making. At the same time, the price of solutions is becoming increasingly high, especially with the acceleration of the rate of development and the diversity of social consequences of modern technologies application. 


\begin{tabular}{l|lr|ll|ll} 
& ISRA (India) & $=\mathbf{1 . 3 4 4}$ & SIS (USA) & $=\mathbf{0 . 9 1 2}$ & ICV (Poland) & $=\mathbf{6 . 6 3 0}$ \\
Impact Factor: & ISI (Dubai, UAE) $=\mathbf{0 . 8 2 9}$ & PUHL (Russia) $=\mathbf{0 . 2 0 7}$ & PIF (India) & $=\mathbf{1 . 9 4 0}$ \\
& GIF (Australia) & $\mathbf{0 . 5 6 4}$ & ESJI (KZ) & $=\mathbf{4 . 1 0 2}$ & IBI (India) & $\mathbf{= 4 . 2 6 0}$ \\
& JIF & $\mathbf{1 . 5 0 0}$ & SJIF (Morocco) $=\mathbf{2 . 0 3 1}$ & & \\
\hline
\end{tabular}

\section{References:}

1. (2018) Handbook of Knowledge Society Foresight. European Foundation for the Improvement of Living and Working Conditions, 169 p. Available: http://edz.bib.unimannheim.de/www-

edz/pdf/ef/03/ef0350en.pdf. $\quad$ (Accessed: 10.03.2018).

2. Glenn, J.C., Gordon, T.J., and Florescu E. (2011) 2011 State of the Future. The Millennium Project; 1 edition, 100 p.

3. Glenn, J.C., and Florescu E. (2017) State of the Future 19.1. The Millennium Project, 238 p.

4. Glenn, J.C., and Florescu E. (2018) State of the Future version 19.0. The Millennium Project, $208 \mathrm{p}$.

5. Organization and Methods. (2005) UNIDO Technology Foresight Manual. V. 1. - 260 p. Available:

http://www.research.gov.ro/img/files_up/12269 11327TechFor_1_unido.pdf. (Accessed: 10.03.2018).

6. (2006) The Global Technology Revolution 2020, Executive Summary: Bio/Nano/Materials/Information Trends, Drivers, Barriers and Social Implications, MG475-NIC (pp. 1-4, Rep.). (2006). RAND Corporation, Available: http://www.foresight- platform.eu/wp-

content/uploads/2011/04/EFMN-Brief-No.-90-

Global-Technology-Revolution-2020.pdf.

(Accessed: 10.03.2018).

7. OECD (2016), OECD Science, Technology and Innovation Outlook 2016, OECD Publishing, Paris,

Available: http://dx.doi.org/10.1787/sti_in_outlook-2016en. (Accessed: 10.03.2018).

8. OECD (2017), OECD Science, Technology and Industry Scoreboard 2017: The digital transformation, OECD Publishing, Paris, Available:

http://dx.doi.org/10.1787/9789264268821-en. (Accessed: 10.03.2018).

9. Anton, P. S., Silberglitt, R., \& Schneider, J. (2001). The Global Technology Revolution. Bio/Nano/Materials Trends and Their Synergies with Information Technology by 2015. (p. 86, Rep. No. MR-1307-NIC). RAND Corporation, Available:

https://www.rand.org/pubs/monograph_reports/ MR1307.html. (Accessed: 10.03.2018).

10. (2018) FOR-LEARN. Online Foresight Guide. JRC. European Commission. - Available: http://forlearn.jrc.ec.europa.eu/guide/A1_keyterms/foresight.htm. (Accessed: 10.03.2018). 